\title{
OPEN Comparison of transoral robotic surgery with other surgeries for obstructive sleep apnea
}

\author{
Yung-An Tsou ${ }^{1,2} \&$ Wen-Dien Chang ${ }^{3 凶}$
}

This study compared the characteristic surgical parameters and clinical effects of transoral robotic surgery (TORS) and other available methods used to alleviate obstructive sleep apnea. Articles on TORS and other surgeries for obstructive sleep apnea were identified in the PubMed and EMBASE databases. Two investigators independently reviewed the articles and classified the data for metaanalysis. The pooled effect sizes of TORS (standardized mean difference; SMD = 2.38 ), coblation tongue base resection (CTBR; SMD = -2.00) and upper airway stimulation (UAS; SMD = -0.94) revealed significant improvement in the apnea-hypopnea index $(A \mathrm{HI} ; \mathrm{p}<0.05)$. The lowest $\mathrm{O}_{2}$ saturation reported was significantly increased following TORS (SMD $=1.43)$, CTBR $(S M D=0.86)$ and UAS (SMD = 1.24, p < 0.05). Furthermore, TORS (SMD = -2.91) and CTBR (SMD = - 1.51, $\mathrm{p}<0.05)$ significantly reduced the Epworth Sleepiness Scale (ESS) score. No significant difference in operation time, success rate, or instances of complication were observed between TORS and the other compared interventions. The use of TORS in obstructive sleep apnea has the same rate of success and failure as other methods of surgical intervention for obstructive sleep apnea with no statistical difference in operation times. The reported clinical effects on the $\mathrm{AHI}$, lowest $\mathrm{O}_{2}$ saturation, and ESS scores of TORS were similar to those of other surgeries.

The number of reported cases of obstructive sleep apnea is increasing. A key factor causing sleep apnea is the narrowing of oropharyngeal space, termed retroglossal and retropalatal airway narrowing ${ }^{1}$. Therefore, surgical methods that target the base of the tongue are especially useful in managing a narrowed oropharynx. The available methods for treating a bulky tongue base include radiofrequency, coblation ${ }^{2}$, transoral robotic surgery ${ }^{3}$, transoral robotic laser surgery ${ }^{4}$, tongue suspension, hyoid suspension surgery ${ }^{5}$, and hypoglossal nerve stimulation ${ }^{3}$. Clinicians and sleep surgeons must employ several diagnostic tools when deciding whether to treat the base of the tongue with surgery ${ }^{6}$. These tools include physical examinations, Muller tests using awake laryngoscopy ${ }^{7}$, drug-induced sleep endoscopy ${ }^{8}$, sleep computed tomography or sleep magnetic resonance imaging, cephalometry and series X-ray assessments ${ }^{9}$. The information obtained from a combination of examinations enables the development of a unique surgical strategy for each patient ${ }^{10}$. Although no single treatment method is currently effective for every patient, several operations have obtained comparable outcomes in treating sleep apnea. This study aimed to perform a systematic review and meta-analysis of the clinical effects and characteristic surgical parameters of transoral robotic surgery (TORS) compared with other surgical interventions for obstructive sleep apnea. The results of this analysis can serve to inform surgeons managing sleep apnea related to the base of the tongue.

\section{Material and methods}

Articles search. The PubMed and EMBASE databases were used searched for articles. The following search strategies were used for the PubMed database: \#1 ("obstructive sleep apnea"[All Fields] OR "transoral robotic surgery"[All Fields]), \#2 ("robotic surgical procedures "[MeSH Terms] OR "sleep apnea syndromes"[MeSH Terms]), \#3 ("surgery" OR "sleep apnea, obstructive"[MeSH Terms]), and \#4 (\#1, \#2AND \#3). The following search strategies were used for the EMBASE database: \# 1 ("obstructive sleep apnea"/exp OR "transoral robotic surgery"), \#2 ("sleep apnea syndromes" OR "surgery"), and \#3 (\#1 AND \#2). The references within the searchedfor articles to provide additional data. The article search strategy was based on the Preferred Reporting Items for Systematic Reviews and Meta-Analyses (PRISMA) statement (Fig. 1).

\footnotetext{
${ }^{1}$ Department of Otolaryngology-Head and Neck Surgery, China Medical University Hospital, Taichung, Taiwan. ${ }^{2}$ Department of Audiology and Speech Pathology, Asia University, Taichung, Taiwan. ${ }^{3}$ Department of Sport Performance, National Taiwan University of Sport, No.16, Sec. 1, Shuang-Shih Rd, Taichung 40404, Taiwan. ${ }^{\varpi}$ email: changwendien@ntupes.edu.tw
} 
Abstracts screened in EMBASE and PubMed

databases electronic databases $(n=76)$

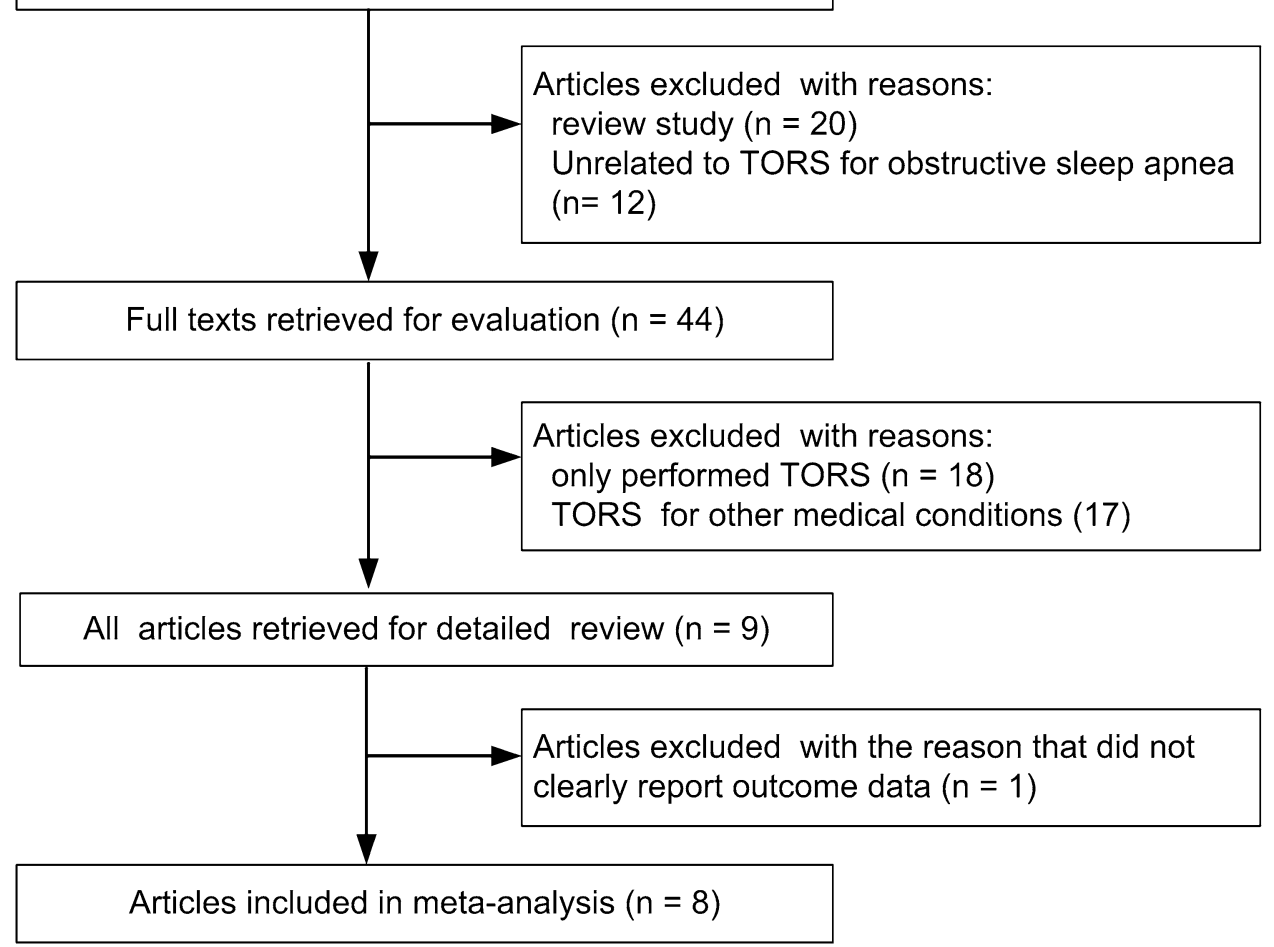

Figure 1. Flowchart of study selection.

Study selection criteria. The articles that compared TORS with various methods were included in the present study and their data enrolled for meta-analysis. Each procedure was evaluated on the basis of the following criteria: apnea-hypopnea index (AHI), lowest $\mathrm{O}_{2}$ saturation, Epworth Sleepiness Scale (ESS) score, complication rate, and success rate. The articles included in this study were human studies written in English that detailed pre-surgery and post-surgery outcomes of TORS compared with other surgical interventions. Articles without data on surgical outcomes, studies on only one particular operation, and reviews on TORS as a treatment for unrelated medical conditions were all excluded. Severity of sleep apnea was diagnosed using attended overnight polysomnography for each patient in the eight studies included, and the scoring system was defined by the American Academy of Sleep Medicine (AASM) $)^{4,11-17}$. Babademez et al. used the AASM 2.2 edition $^{12}$, and Hwang et al. and Lan et al. used the AASM 2.5 edition to measure overnight PSG ${ }^{11,13}$. The other referenced studies scored patients using the AASM 2 nd edition ${ }^{4,14-17}$. Pre-operative and post-operative apnea were defined as more than $10 \mathrm{~s}$ of no or decreased oronasal airflow. Hypopnea was defined as a discernible fall in oronasal flow with $\mathrm{SpO}_{2}$ desaturation. All the included studies used the AASM scoring manual for evaluation. Therefore, the obstructive sleep apnea severity and surgical outcomes are comparable.

Data extraction and analysis. Two investigators independently reviewed the articles and obtained study design, intervention method comparison, study size, and clinical outcomes data. Surgical outcome data were divided into the following categories: AHI, lowest $\mathrm{O}_{2}$ saturation, and ESS score. Furthermore, data regarding surgery efficiency and efficacy were collected, including operation time, complication rate, and success rate. The quality of data obtained from the articles was determined through the Quality Assessment of Diagnostic Accuracy Studies-2 (QUADAS-2) tool. A funnel plot was used to assess publication bias. The success rate, defined as $\mathrm{AHI}<20$ events/h after treatment and $\geq 50 \%$ reduction of pre-operative AHI, and heterogeneity were studied through meta-analysis.

Statistical analysis. All data were analyzed using MedCalc 14 (MedCalc Software, Oostende, Belgium). The continuous variables (AHI, lowest $\mathrm{O}_{2}$ saturation, and ESS score) were collected for both the pre-intervention and post-intervention states. Standardized mean differences (SMD) with 95\% confidence intervals (CI) were used to analyze the effect sizes for each study. Pooled SMD with 95\% CIs were estimated across the same interventions. TORS was compared with alternative interventions for obstructive sleep apnea, and SMDs with 95\% CIs were used to compare continuous variables of surgery efficiency. Moreover, the success and complication rates, which were categorical variables, were assessed using the odds ratio and relative risk, respectively. The $\mathrm{I}^{2}$ 


\begin{tabular}{|c|c|c|c|c|c|c|c|}
\hline \multirow[b]{2}{*}{ Author (year) } & \multicolumn{4}{|l|}{ Risk of bias } & \multicolumn{3}{|c|}{ Applicability concerns } \\
\hline & Patient selection & Index test & $\begin{array}{l}\text { Reference } \\
\text { standard }\end{array}$ & $\begin{array}{l}\text { Flow and } \\
\text { timing }\end{array}$ & Patient selection & Index test & $\begin{array}{l}\text { Reference } \\
\text { standard }\end{array}$ \\
\hline Hwang $(2019)^{11}$ & $\ddot{\theta}$ & $\ddot{\theta}$ & 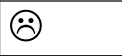 & $?$ & (:) & () & () \\
\hline $\begin{array}{l}\text { Babademez } \\
(2019)^{12}\end{array}$ & $\theta$ & $\ddot{\theta}$ & $\theta$ & $?$ & :) & (:) & ;) \\
\hline Lan $(2019)^{13}$ & $\ddot{\theta}$ & $\ddot{\theta}$ & $\ddot{\theta}$ & $?$ & (:) & (:) & (:) \\
\hline Huntley $(2019)^{14}$ & 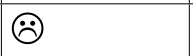 & $\ddot{\theta}$ & $\ddot{\theta}$ & $?$ & (i) & (;) & (i) \\
\hline $\mathrm{Yu}(2019)^{15}$ & 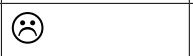 & 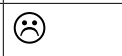 & 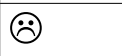 & $?$ & (i) & (;) & (i) \\
\hline Aynacı $(2018)^{16}$ & (i) & $?$ & (;) & (i) & (i) & (:) & (i) \\
\hline Karaman $(2017)^{4}$ & $\ddot{\theta}$ & $\ddot{\theta}$ & $\ddot{\theta}$ & $?$ & $\odot$ & (:) & (:) \\
\hline Folk $(2017)^{17}$ & $\ddot{\theta}$ & $\ddot{\theta}$ & 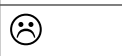 & $?$ & (:) & (:) & (:) \\
\hline
\end{tabular}

Table 1. The results of QUADAS-2 in included studies. (-), low risk; $: ;$, high risk, ?, unclear risk.

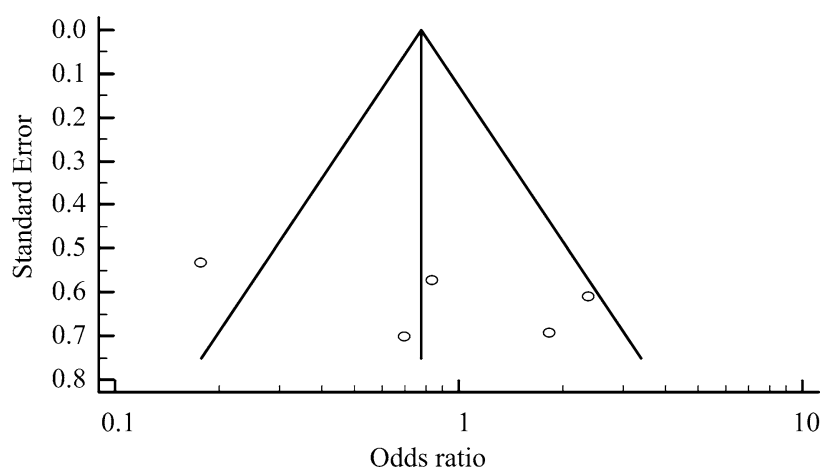

Figure 2. Funnel plot analysis of publication bias in included studies.

statistic for heterogeneity was employed to estimate fixed or random effect models. A value of $\mathrm{p}<0.05$ was considered statistically significant.

\section{Results}

In January 2020, 76 articles were identified in a preliminary search, and 8 of these articles met the criteria for review $^{4,11-17}$. The results of QUADAS-2 assessment of the included articles are illustrated in Table 1. A funnel plot was used to examine bias for meta-analysis (Fig. 2) and revealed a significant treatment effect in these studies $(\mathrm{p}<0.05)$. Among the included studies, six were retrospective $\mathrm{e}^{11-15,17}$, one had a pre-post-test design ${ }^{16}$, and one was prospective ${ }^{4}$. In total, 188 patients with obstructive sleep apnea treated with TORS and 230 cases treated with alternative interventions were included in the analysis. Three studies investigated coblation tongue base resection $(C T B R \text {, total } n=79)^{11-13}$, and two studies investigated upper airway stimulation (UAS, total $\left.n=105\right)^{14,15}$. Three articles reported on radiofrequency $(n=20), \mathrm{CO}_{2}$ laser $(n=10)$, and endoscopic partial midline glossectomy $(E P M G, n=16)^{4,16,17}$. The success numbers of TORS and alternative interventions are represented in Table 2. However, the post-operation cure rate in the article of $\mathrm{Yu}$ et al. was defined as $\mathrm{AHI}<5^{15}$, whereas other studies used the success rate.

AHI, lowest $\mathrm{O}_{2}$ saturation, and ESS score after TORS and alternative interventions. Preoperation and postoperation AHIs were reported in all the papers (Table 2) ${ }^{4,11-17}$. All patients treated with TORS displayed a significant decrease in AHI $(\mathrm{p}<0.05)$, and the total random effect was -2.38 (a decline in average AHI from 41.56 to 17.10 events/h), as displayed in Table 3. The pooled effect sizes of CTBR (a decline in average AHI from 42.92 to 17.42 events/h; total random effect $=-2.00$ ) and UAS (a decline in average AHI from 38.58 to 7.21 vents/h; total fixed effect $=-0.94)$ also revealed significant improvement in AHI $(p<0.05)$. Aynac1 et al., Karaman et al., and Folk et al. reported mean effects sizes on the AHI of $-2.42,-5.96$ and -0.66 , respectively $y^{4,16,17}$. These studies did not include pooled effect sizes of $\mathrm{AHI}$ for radiofrequency, $\mathrm{CO}_{2}$ laser or EPMG.

Six studies measured the lowest $\mathrm{O}_{2}$ saturation before and after the operation ${ }^{11,13-17}$. As illustrated in Table 4, a comparison of SMD in TORS revealed a significant increase in lowest $\mathrm{O}_{2}$ saturation (increase in average lowest $\mathrm{O}_{2}$ saturation from 79.83 to $86.81 \%$; total random effect $=1.43, \mathrm{p}<0.05$ ). The pooled effect sizes for CTBR (increase in average lowest $\mathrm{O}_{2}$ saturation from 76.25 to $83.01 \%$; total fixed effect $=0.86$ ) and UAS (an increase in average lowest $\mathrm{O}_{2}$ saturation from 79.45 to $85.55 \%$; total fixed effect $=1.24$ ) also revealed significant increases in 


\begin{tabular}{|c|c|c|c|c|c|c|c|}
\hline \multirow[b]{2}{*}{ Author (year) } & \multirow[b]{2}{*}{ Design } & \multirow[b]{2}{*}{ Intervention (n) } & \multicolumn{3}{|c|}{ Obstructive sleep apnea patients } & \multirow[b]{2}{*}{ Success after intervention (n) } & \multirow[b]{2}{*}{ Clinical outcomes } \\
\hline & & & Age & Gender (M/F) & BMII $\left(\mathbf{k g} / \mathbf{m}^{2}\right)$ & & \\
\hline \multirow{2}{*}{ Hwang $(2019)^{11}$} & \multirow{2}{*}{ Retrospective } & TORS (16) & $45.1 \pm 13.4$ & $14 / 2$ & $25.8 \pm 3.4$ & 12 & $\begin{array}{l}\text { Decrease } \mathrm{AHI}^{*} \text { and ESS, and } \\
\text { increase lowest } \mathrm{O}_{2} \text { saturation }\end{array}$ \\
\hline & & CTBR (29) & $39.8 \pm 10.8$ & $26 / 3$ & $26.8 \pm 2.8$ & 18 & $\begin{array}{l}\text { Decrease } \mathrm{AHI}^{*} \text { and ESS, and } \\
\text { increase lowest } \mathrm{O}_{2} \text { saturation }\end{array}$ \\
\hline \multirow{2}{*}{ Babademez $(2019)^{12}$} & \multirow{2}{*}{ Retrospective } & TORS (37) & $40.9 \pm 9.2$ & $28 / 9$ & $27.0 \pm 4.4$ & 28 & Decrease $\mathrm{AHI}^{*}$ and $\mathrm{ESS}^{*}$ \\
\hline & & CTBR (33) & $39.4 \pm 8.5$ & $25 / 8$ & $28.3 \pm 3.9$ & 26 & Decrease $\mathrm{AHI}^{*}$ and $\mathrm{ESS}^{*}$ \\
\hline \multirow{2}{*}{ Lan $(2019)^{13}$} & \multirow{2}{*}{ Retrospective } & TORS (16) & $39.4 \pm 12.3$ & $15 / 1$ & $28.2 \pm 3.8$ & 8 & $\begin{array}{l}\text { Decrease } \mathrm{AHI}^{*} \text { and } \mathrm{ESS}^{*} \text {, and } \\
\text { increase lowest } \mathrm{O}_{2} \text { saturation }\end{array}$ \\
\hline & & CTBR (17) & $38.7 \pm 11.5$ & $13 / 4$ & $27.4 \pm 5.6$ & 10 & $\begin{array}{l}\text { Decrease } \mathrm{AHI}^{*} \text { and ESS } \text { ES }^{*} \text { and } \\
\text { increase lowest } \mathrm{O}_{2} \text { saturation }\end{array}$ \\
\hline \multirow{2}{*}{ Huntley $(2019)^{14}$} & \multirow{2}{*}{ Retrospective } & TORS (24) & $46.4 \pm 13.9$ & $20 / 4$ & $29.6 \pm 3.8$ & 13 & $\begin{array}{l}\text { Decrease AHI and ESS, and } \\
\text { increase lowest } \mathrm{O}_{2} \text { saturation }\end{array}$ \\
\hline & & UAS(76) & $61.9 \pm 12.0$ & $50 / 26$ & $29.4 \pm 4.1$ & 66 & $\begin{array}{l}\text { Decrease AHI and ESS, and } \\
\text { increase lowest } \mathrm{O}_{2} \text { saturation }\end{array}$ \\
\hline \multirow{2}{*}{$\mathrm{Yu}(2019)^{15}$} & \multirow{2}{*}{ Retrospective } & TORS(20) & $53^{\mathrm{a}}$ & $16 / 4$ & $<35$ & $15^{\mathrm{b}}$ & $\begin{array}{l}\text { Decrease AHI and ESS, and } \\
\text { increase lowest } \mathrm{O}_{2} \text { saturation }\end{array}$ \\
\hline & & UAS(29) & $62^{\mathrm{a}}$ & $25 / 4$ & $<35$ & $23^{\mathrm{b}}$ & $\begin{array}{l}\text { Decrease AHI and ESS, and } \\
\text { increase lowest } \mathrm{O}_{2} \text { saturation }\end{array}$ \\
\hline \multirow{2}{*}{ Aynacı $(2018)^{16}$} & \multirow{2}{*}{ Pre-post test } & TORS(20) & $45.0 \pm 7.1$ & $16 / 4$ & NA & 20 & $\begin{array}{l}\text { Decrease } \mathrm{AHI}^{*} \text { and ESS } \\
\text { increase lowest } \mathrm{O}_{2} \text { saturation } \\
\end{array}$ \\
\hline & & Radiofrequency $(20)$ & $41.7 \pm 8.4$ & $17 / 3$ & NA & 20 & $\begin{array}{l}\text { Decrease } \mathrm{AHI}^{*} \text { and } \mathrm{ESS}^{*} \text {, and } \\
\text { increase lowest } \mathrm{O}_{2} \text { saturation }\end{array}$ \\
\hline \multirow{2}{*}{ Karaman $(2017)^{4}$} & \multirow{2}{*}{ Prospective } & TORS(10) & \multirow{2}{*}{$45.1 \pm 7.2$} & \multirow{2}{*}{$16 / 4$} & \multirow{2}{*}{ NA } & 10 & $\begin{array}{l}\text { Decrease AHI and ESS, and } \\
\text { increase lowest } \mathrm{O}_{2} \text { saturation }\end{array}$ \\
\hline & & $\mathrm{CO}_{2}$ laser(10) & & & & 10 & $\begin{array}{l}\text { Decrease AHI and ESS, and } \\
\text { increase lowest } \mathrm{O}_{2} \text { saturation }\end{array}$ \\
\hline \multirow{2}{*}{ Folk $(2017)^{17}$} & \multirow{2}{*}{ Retrospective } & TORS(45) & $48.2 \pm 11.6$ & $33 / 12$ & $32.3 \pm 4.8$ & 34 & $\begin{array}{l}\text { Decrease } \mathrm{AHI}^{*} \text { and ESS}, \text { and } \\
\text { increase lowest } \mathrm{O}_{2} \text { saturation }\end{array}$ \\
\hline & & EPMG(16) & $46.3 \pm 8.4$ & $12 / 4$ & $32.5 \pm 3.5$ & 9 & $\begin{array}{l}\text { Decrease AHI and ESS, and } \\
\text { increase lowest } \mathrm{O}_{2} \text { saturation }\end{array}$ \\
\hline
\end{tabular}

Table 2. Overview of studies on TORS and compared studies. $N A$, not available; $M / F$, male/female; $B M I$, body mass index; TORS, transoral robotic surgery; CTBS, coblation tongue base resection; UAS, upper airway stimulation; EPMG, endoscopic partial midline glossectomy; AHI, apnea-hypopnea index; ESS, Epworth Sleepiness Scale. ${ }^{\mathrm{a}}$ Average age; ${ }^{\mathrm{b}}$ cure no. of patients; ${ }^{\star}$ Statistical significance in pre- and post-operation $(\mathrm{p}<0.05)$.

lowest $\mathrm{O}_{2}$ saturation $(\mathrm{p}<0.05)$. Only one study on radiofrequency ${ }^{16}$ and one on $\mathrm{EPMG}^{17}$ reported that of lowest $\mathrm{O}_{2}$ saturation was improved, and the effect sizes were 2.57 and 0.32 , respectively.

As displayed in Table 5, five studies measured ESS score before and after the operation ${ }^{11-13,16,17}$. Comparison of the effect size after treatment with TORS revealed a significant decrease in ESS scores (decline in average ESS score from 12.82 to 5.33; total random effect $=-2.91, \mathrm{p}<0.05)$. Comparison of the pre-operative and postoperative ESS scores in three studies revealed that CTBR caused a significant decrease (decline in average ESS score from 10.66 to 6.43 ; total random effect $=-1.51, \mathrm{p}<0.05)$. However, the ESS scores of patients treated with CTBR were higher than those of patients treated with TORS. One article on radiofrequency ${ }^{16}$ and one article on $\mathrm{EPMG}^{17}$ revealed a reduction in ESS score at -4.19 and -0.83 , respectively.

Operation time in TORS and compared interventions. Three articles reported data on operation time ${ }^{11,12,16}$. A comparison of effect size between TORS and the alternative interventions, CTBR and radiofrequency, revealed no significant differences in operation time for the treatment of obstructive sleep apnea ( $\mathrm{p}>0.05$, Fig. 3).

Success rate and complication rate in TORS and compared interventions. Seven studies compared the success rate of TORS with that of alternative interventions (CTBR, UAS, radiofrequency, $\mathrm{CO}_{2}$ laser and EPMG) $)^{4,11-14,16,17}$. The odds ratio revealed that no significant differences were observed in the success rates using TORS and other interventions for obstructive sleep apnea (pooled odds ratio $=0.82, p>0.05$, Fig. 4). Five studies reported the complication rates after treatment with TORS or a comparedintervention (CTBR, UAS, or radiofrequency $)^{11-14,16}$. An assessment of the relative risk revealed that the complication rate of TORS was higher than those of the alternative interventions. However, this difference was also non-significant (pooled relative risk $=1.30$, $\mathrm{p}>0.05$, Fig. 5). 


\begin{tabular}{|c|c|c|c|c|c|c|c|}
\hline Author (year) & Intervention & $\mathbf{n}$ & Weight (\%) & SMD & SE & 95\% CI & $\mathbf{p}$ \\
\hline Hwang $(2019)^{11}$ & TORS & 16 & 11.42 & -1.82 & 0.41 & -2.66 to -0.97 & \\
\hline Babademez (2019) $)^{\mathrm{a}, 12}$ & TORS & 37 & 12.01 & -2.71 & 0.32 & -3.34 to -2.07 & \\
\hline Babademez (2019) & TORS & 37 & 12.06 & -2.55 & 0.31 & -3.17 to -1.93 & \\
\hline $\operatorname{Lan}(2019)^{13}$ & TORS & 16 & 11.65 & -1.24 & 0.37 & -2.01 to 0.47 & \\
\hline Huntley (2019) ${ }^{14}$ & TORS & 24 & 12.17 & -0.66 & 0.29 & -1.25 to -0.08 & \\
\hline Yu $(2019)^{15}$ & TORS & 20 & 11.89 & -1.26 & 0.34 & -1.95 to -0.57 & \\
\hline Aynac1 $(2018)^{16}$ & TORS & 20 & 8.16 & -7.06 & 0.84 & -8.78 to -5.34 & \\
\hline Karaman $(2017)^{4}$ & TORS & 10 & 8.21 & -4.58 & 0.84 & -6.34 to -2.81 & \\
\hline Folk $(2017)^{17}$ & TORS & 45 & 12.43 & -1.63 & 0.24 & -2.11 to -1.15 & \\
\hline Total random effect & TORS & 225 & 100.00 & -2.38 & 0.40 & -3.15 to -1.59 & 0.001 \\
\hline \multicolumn{3}{|l|}{ Heterogeneity test } & \multicolumn{4}{|c|}{$\mathrm{Q}=83.29, \mathrm{df}=8, \mathrm{I}^{2}=90.40 \%$} & 0.001 \\
\hline Hwang $(2019)^{11}$ & CTBR & 29 & 25.56 & -1.64 & 0.30 & -2.24 to -1.04 & \\
\hline Babademez (2019) ${ }^{\mathrm{a}, 12}$ & CTBR & 33 & 24.49 & -3.12 & 0.36 & -3.85 to -2.40 & \\
\hline Babademez $(2019)^{\mathrm{b}, 12}$ & CTBR & 33 & 25.12 & -2.52 & 0.32 & -3.18 to -1.87 & \\
\hline $\operatorname{Lan}(2019)^{13}$ & CTBR & 17 & 24.82 & -0.72 & 0.34 & -1.42 to -0.01 & \\
\hline Total random effect & CTBR & 112 & 100 & -2.00 & 0.50 & -2.99 to -1.01 & 0.001 \\
\hline \multicolumn{3}{|l|}{ Heterogeneity test } & \multicolumn{4}{|c|}{$\mathrm{Q}=27.13, \mathrm{df}=3, \mathrm{I}^{2}=88.94 \%$} & 0.001 \\
\hline Huntley $(2019)^{14}$ & UAS & 76 & 68.82 & -0.80 & 0.23 & -1.27 to -0.33 & \\
\hline $\mathrm{Yu}(2019)^{15}$ & UAS & 29 & 31.18 & -1.25 & 0.35 & -1.97 to -0.53 & \\
\hline Total fixed effect & UAS & 105 & 100 & -0.94 & 0.19 & -1.33 to -0.55 & 0.001 \\
\hline \multicolumn{3}{|l|}{ Heterogeneity test } & \multicolumn{4}{|c|}{$\mathrm{Q}=1.10, \mathrm{df}=1, \mathrm{I}^{2}=9.48 \%$} & 0.29 \\
\hline Aynac1 $(2018)^{16}$ & Radiofrequency & 20 & NA & -2.42 & 0.41 & -3.25 to -1.58 & \\
\hline Karaman $(2017)^{4}$ & $\mathrm{CO} 2$ laser & 10 & NA & -5.96 & 1.03 & -8.14 to -3.79 & \\
\hline Folk $(2017)^{17}$ & EPMG & 16 & NA & -0.66 & 0.35 & -1.39 to 0.05 & \\
\hline
\end{tabular}

Table 3. Effect sizes on AHI among the interventions. SMD standardized mean difference, SE standard error, CI confidence intervals, TORS transoral robotic surgery, CTBS coblation tongue base resection, UAS upper airway stimulation, EPMG endoscopic partial midline glossectomy.

\begin{tabular}{|c|c|c|c|c|c|c|c|}
\hline Author (year) & Intervention & $\mathbf{n}$ & Weight (\%) & SMD & SE & $95 \% \mathrm{CI}$ & $\mathbf{p}$ \\
\hline Hwang $(2019)^{11}$ & TORS & 16 & 17.18 & 0.81 & 0.35 & 0.07 to 1.54 & \\
\hline Lan $(2019)^{13}$ & TORS & 16 & 16.85 & 1.56 & 0.39 & 0.75 to 2.37 & \\
\hline Huntley $(2019)^{14}$ & TORS & 24 & 17.76 & 0.36 & 0.28 & -0.21 to 0.93 & \\
\hline $\mathrm{Yu}(2019)^{15}$ & TORS & 20 & 17.21 & 0.23 & 0.35 & -0.50 to 0.96 & \\
\hline Aynacı $(2018)^{16}$ & TORS & 20 & 12.75 & 6.52 & 0.79 & 4.92 to 8.13 & \\
\hline Folk $(2017)^{17}$ & TORS & 45 & 18.25 & 0.51 & 0.21 & 0.09 to 0.93 & \\
\hline Total random effect & TORS & 141 & 100 & 1.43 & 0.49 & 0.45 to 2.41 & 0.004 \\
\hline \multicolumn{3}{|l|}{ Heterogeneity test } & \multicolumn{4}{|c|}{$\mathrm{Q}=62.50, \mathrm{df}=9, \mathrm{I} 2=92 \%$} & 0.001 \\
\hline Hwang $(2019)^{11}$ & CTBR & 29 & 60.36 & 1.06 & 0.27 & 0.50 to 1.61 & \\
\hline Lan $(2019)^{13}$ & CTBR & 17 & 39.64 & 0.57 & 0.34 & -0.12 to 1.27 & \\
\hline Total fixed effect & CTBR & 46 & 100 & 0.86 & 0.21 & 0.44 to 1.29 & 0.001 \\
\hline \multicolumn{3}{|l|}{ Heterogeneity test } & \multicolumn{4}{|c|}{$\mathrm{Q}=1.22, \mathrm{df}=1, \mathrm{I} 2=18.32 \%$} & 0.26 \\
\hline Huntley $(2019)^{14}$ & UAS & 76 & 74.74 & 1.33 & 0.17 & 0.98 to 1.68 & \\
\hline $\mathrm{Yu}(2019)^{15}$ & UAS & 29 & 25.26 & 0.978 & 0.30 & 0.35 to 1.59 & \\
\hline Total fixed effect & UAS & 105 & 100 & 1.24 & 0.15 & 0.93 to 1.54 & 0.001 \\
\hline \multicolumn{3}{|l|}{ Heterogeneity test } & \multicolumn{4}{|c|}{$\mathrm{Q}=1.22, \mathrm{df}=1, \mathrm{I} 2=18.32 \%$} & 0.31 \\
\hline Aynacı $(2018)^{16}$ & Radiofrequency & 20 & $\mathrm{NA}$ & 2.57 & 0.42 & 1.71 to 3.43 & \\
\hline Folk $(2017)^{17}$ & EPMG & 16 & NA & 0.32 & 0.34 & -0.38 to 1.02 & \\
\hline
\end{tabular}

Table 4. Effect sizes on lowest $\mathrm{O}_{2}$ saturation among the interventions. $S M D$ standardized mean difference, $S E$ standard error, CI confidence intervals, TORS transoral robotic surgery, CTBS coblation tongue base resection, $U A S$ upper airway stimulation, EPMG endoscopic partial midline glossectomy. 


\begin{tabular}{|c|c|c|c|c|c|c|c|}
\hline Author (year) & Intervention & $\mathbf{n}$ & Weight (\%) & SMD & SE & $95 \% \mathrm{CI}$ & $\mathbf{p}$ \\
\hline Hwang $(2019)^{11}$ & TORS & 16 & 21.02 & -0.92 & 0.36 & -1.66 to -0.19 & \\
\hline Babademez $(2019)^{12}$ & TORS & 37 & 21.01 & -3.39 & 0.36 & -4.11 to -2.67 & \\
\hline $\operatorname{Lan}(2019)^{13}$ & TORS & 16 & 21.02 & -0.81 & 0.35 & -1.54 to -0.08 & \\
\hline Aynacı $(2018)^{16}$ & TORS & 20 & 15.43 & -9.06 & 1.06 & -11.21 to -6.92 & \\
\hline Folk $(2017)^{17}$ & TORS & 45 & 21.52 & -2.01 & 0.25 & -2.52 to -1.50 & \\
\hline Total random effect & TORS & 134 & 100 & -2.91 & 0.76 & -4.40 to -1.41 & 0.001 \\
\hline \multicolumn{3}{|l|}{ Heterogeneity test } & \multicolumn{4}{|c|}{$\mathrm{Q}=78.97, \mathrm{df}=4, \mathrm{I}^{2}=94.93 \%$} & 0.001 \\
\hline Hwang $(2019)^{11}$ & CTBR & 29 & 33.92 & -0.51 & 0.26 & -1.04 to 0.01 & \\
\hline Babademez $(2019)^{12}$ & CTBR & 33 & 32.79 & -3.57 & 0.39 & -4.35 to -2.78 & \\
\hline $\operatorname{Lan}(2019)^{13}$ & CTBR & 17 & 33.30 & -0.51 & 0.34 & -1.20 to 0.18 & \\
\hline Total random effect & CTBR & 79 & 100.00 & -1.51 & 0.92 & -3.33 to 0.30 & 0.10 \\
\hline \multicolumn{3}{|l|}{ Heterogeneity test } & \multicolumn{4}{|c|}{$\mathrm{Q}=46.91, \mathrm{df}=2, \mathrm{I}^{2}=95.74 \%$} & 0.001 \\
\hline Aynacı $(2018)^{16}$ & Radiofrequency & 20 & NA & -4.19 & 0.56 & -5.33 to -3.05 & \\
\hline Folk $(2017)^{17}$ & EPMG & 16 & NA & -0.83 & 0.36 & -1.56 to -0.09 & \\
\hline
\end{tabular}

Table 5. Effect sizes on ESS among the interventions. SMD standardized mean difference, $S E$ standard error, $C I$ confidence intervals, TORS transoral robotic surgery, CTBR coblation tongue base resection, EPMG endoscopic partial midline glossectomy.

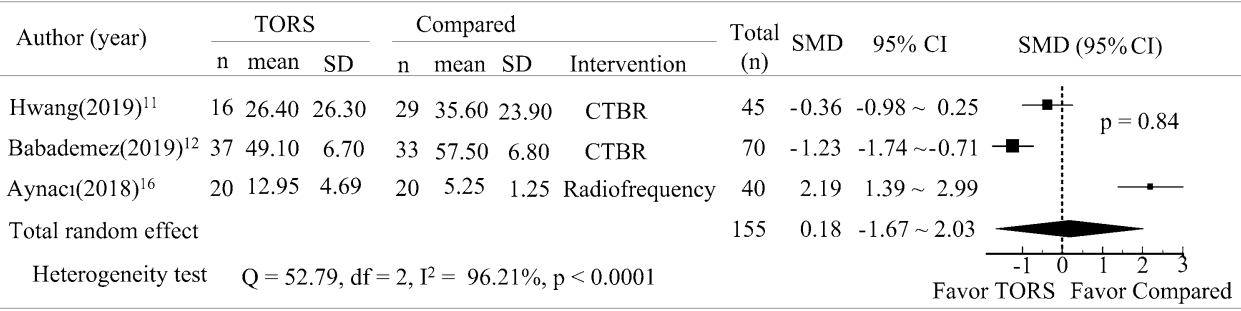

Figure 3. Forest plot depicting operation time between TORS and compared intervention.

\begin{tabular}{|c|c|c|c|c|c|c|}
\hline \multirow{2}{*}{ Author (year) } & \multirow{2}{*}{$\frac{\text { TORS }}{\text { Success rate }(\%)}$} & \multicolumn{2}{|c|}{ Compared } & \multirow{2}{*}{$\begin{array}{l}\text { Odds } \\
\text { ratio }\end{array}$} & \multirow{2}{*}{$95 \% \mathrm{CI}$} & \multirow{2}{*}{ Odd ratio $(95 \% \mathrm{CI})$} \\
\hline & & Success rate $(\%)$ & Intervention & & & \\
\hline Hwang $(2019)^{11}$ & 75.00 & 62.07 & CTBR & 1.83 & $0.47 \sim 7.12$ & \\
\hline Babademez $(2019)^{12}$ & 75.68 & 78.79 & CTBR & 0.83 & $0.27 \sim 2.57$ & \\
\hline $\operatorname{Lan}(2019)^{13}$ & 50.00 & 58.82 & CTBR & 0.70 & $0.17 \sim 2.77$ & \\
\hline Huntley $(2019)^{14}$ & 54.17 & 86.84 & UAS & 0.17 & $0.06 \sim 0.50$ & 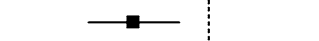 \\
\hline Aynac1 $(2018)^{16}$ & 100.00 & 100.00 & Radiofrequency & & & \\
\hline $\operatorname{Karaman}(2017)^{17}$ & 100.00 & 100.00 & $\mathrm{CO}_{2}$ laser & & & \\
\hline Folk $(2017)^{18}$ & 75.56 & 56.25 & EPMG & 2.40 & $0.72 \sim 7.97$ & \\
\hline \multicolumn{4}{|l|}{ Total random effect } & 0.82 & $0.31 \sim 2.16$ & $\mathrm{p}=0.32$ \\
\hline Heterogeneity test & \multicolumn{3}{|c|}{$\mathrm{Q}=12.59, \mathrm{df}=4, \mathrm{I}^{2}=68.24 \%, \mathrm{p}<0.01$} & & & 0.01 \\
\hline
\end{tabular}

Figure 4. Forest plot depicting success rate between TORS and compared intervention.

\section{Discussion}

TORS is a novel and technologically advanced surgery that has been used to treat obstructive sleep apnea. This systematic review was conducted to compare the clinical effects of the surgical interventions, such as TORS, CTBR, UAS, radiofrequency, $\mathrm{CO}_{2}$ laser, and EPMG. Clinical outcome (AHI, lowest $\mathrm{O} 2$ saturation, and ESS score) and surgical effect (operation time, success rate, and complication rate) data for TORS and alternative interventions were compared using meta-analysis. The eight published articles included in our analysis are summarized in Table 2. Our results demonstrated that TORS, and the other interventions, significantly reduced the $\mathrm{AHI}$ and ESS score and increased the lowest $\mathrm{O}_{2}$ saturation in patients with obstructive sleep apnea patients. No significant differences in operation time, success rate, or complication rate were observed between TORS and the compared interventions ( $\mathrm{p}>0.05)$.

A meta-analysis of the procedures revealed that the pooled SMD in the AHI, lowest $\mathrm{O}_{2}$ saturation, and ESS score for TORS were larger than those for CTBR and UAS. All three interventions had significant effects on 


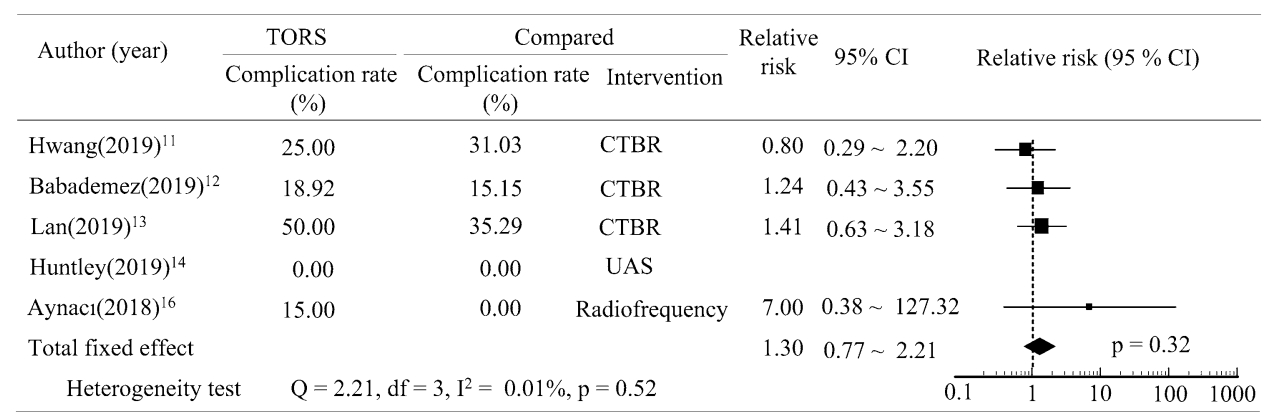

Figure 5. Forest plot depicting complication rate between TORS and compared intervention.

obstructive sleep apnea $(\mathrm{p}<0.05)$. However, UAS is currently considered to be the optimal method for widening the oropharynx and retroglossal space ${ }^{18}$. The Food and Drug Administration approves of UAS in patients with tongue base anterior-posterior collapse and an AHI of $<50 / \mathrm{h}^{19}$. Huntley et al. indicated that the UAS surgical procedure is a multilevel procedure and focuses on tongue base obstruction and airway caliber in patients with obstructive sleep apnea. CTBR has the advantages of minimal training time and lower cost than TORS ${ }^{14}$. However, the excitement of electrodes on the instrument can create ionized particles in saline solution and disrupt intercellular bonds. The outcomes of CTBR show unfavorable effects of necrosis and scar tissue formation in patients who underwent the procedure ${ }^{20}$. However, in our systematic review, we found that patients treated with TORS had reduction in both AHI and lowest $\mathrm{O}_{2}$ saturation values as well as ESS improvement, and the effect size of TORS was slightly superior to those of CTBR and UAS. We thought that this is because TORS is performed using a real layer resection of lingual tonsils and a partial resection of tongue base muscle. Therefore, the volume reduction is more prominent than the volume reduction following radiofrequency or CTBR. Radiofrequency and CTBR may exhibit a firewall effect, meaning that the volume-reduction effects may be minimized by denatured tissue blocking energy transfer from the core of the surgical devices. Furthermore, UAS electric titration is not sufficiently powerful for most cases of huge tongue collapse or lateral pharyngeal collapse. The rate of increased volume varies depending on the quantity of electric power used, which also explains the unstable improvements in $\mathrm{AHI}$, lowest $\mathrm{O}_{2}$ saturation, and ESS score.

We identified few data comparisons of AHI, lowest $\mathrm{O}_{2}$ saturation and ESS score following treatment with radiofrequency, $\mathrm{CO}_{2}$ laser, and EPMG. The radiofrequency method reduces tissue volume using high-frequency current flow to apply a selective temperatures ${ }^{21}$. Patients with obstructive sleep apnea had decreased snoring and improved respiratory effort when treated with radiofrequency applied to the soft palate ${ }^{22}$. The results reported by Aynaci et al. indicated that the radiofrequency method had better outcomes than TORS in terms of operation duration, length of post-operation hospitalization, and oral feeding duration ${ }^{16}$. Furthermore, $15 \%$ of complications from all methods were found after treatment with TORS, while no complications occurred after treatment with radiofrequency. $\mathrm{CO}_{2}$ laser treatment is a cost-effective surgery that causes less thermal damage from tissue cutting and coagulation than alternative methods ${ }^{23}$. Karaman et al. determined that the $\mathrm{CO}_{2}$ laser method has a lower complication rate, operation duration, length of postoperative hospitalization, and oral feeding time than TORS. After treatment with $\mathrm{CO}_{2}$ laser, patients with sleep apnea patients had a significantly lower AHI and significantly less postoperative pain $(\mathrm{p}<0.05)^{4}$. Furthermore, tissue resection is easier using $\mathrm{CO}_{2}$ laser treatment compared with TORS ${ }^{4,24}$. EPMG was reported to be an effective surgical procedure in treating obstructive sleep apnea ${ }^{25}$. Folk et al. compared the changes in AHI, lowest $\mathrm{O}_{2}$ saturation, and ESS score pre- and post-operation, but no significant differences were observed $(\mathrm{p}>0.05)^{17}$. TORS has been demonstrated to have superior clinical effects to EPMG in patients with sleep apnea. Few studies have compared TORS to methods such as radiofrequency, $\mathrm{CO}_{2}$ laser, and EPMG. Therefore, discussion regarding the clinical implications of these interventions has been limited.

Currently, surgical reduction of retroglossal airway obstruction is a common method for treating tongue base collapse. Effect parameters (AHI, lowest $\mathrm{O}_{2}$ saturation, and ESS score) were used in the present study to assess pre- and post-operation conditions. The information provided by each article was not sufficient to perform a meta-analysis of surgical characteristics. Only three articles provided operation time data ${ }^{11,12,16}$. No significant differences were observed in operation times among TORS, CTBR, and radiofrequency $(p>0.05)$. However, when performed by an experienced surgeon with a low docking times, TORS was less time consuming than the other interventions. We also identified no significant differences in the success and complication rates of TORS and other surgical interventions for obstructive sleep apnea $(p>0.05)$. The volume of the tongue base is considered to be unrelated to surgical outcomes if Sher's criteria are used (post-operative AHI $<20$ and $>50 \%$ reduction of preoperative AHI). However, the AHI and lowest $\mathrm{O}_{2}$ saturation displayed larger improvements after TORS than other interventions. The TORS and CTBR methods of tongue-base reduction exhibited competitive surgical results ${ }^{26}$. Furthermore, no significant differences in ESS score, lowest $\mathrm{O}_{2}$ saturation, operation time, or complication rate were observed between the two methods. A previous study revealed increased $\mathrm{O}_{2}$ saturation and a reduction in AHI after treatment with TORS, however, the study also reported that TORS resulted in a higher pain score ${ }^{27}$. Hoff et al. reported that the TORS procedure had a shorter operation times than other interventions ${ }^{28}$. Studies on CTBR reported comorbidities of bleeding, pain, transient dysphagia, and dysgeusia ${ }^{29,30}$. Studies reported a taste disturbance rate of $13.8-17.5 \%$ following CTBR, comparable to the reported dysgeusia rates in three 
systematic review studies on TORS $29,31,32$. We determined that TORS led to a higher AHI reduction even with a higher baseline in some studies ${ }^{6,13,26}$. However, the TORS still yielded results were comparable to those of other methods such as CTBR or $\mathrm{CO}_{2}$ laser surgery. TORS has been demonstrated to lower the AHI and reduce the severity of sleep apnea by reducing tongue base volume. However, the volume of tongue reduction is not proportional to the AHI reduction in each patient. A tailor-made surgical strategies and personalized treatments should be considered for each patient with sleep apnea. For patients with severe obstructive sleep apnea, surgical methods, such as TORS or CTBR, are a viable option for tongue base management. TORS is beneficial in terms of increasing $\mathrm{O}_{2}$ saturation to $90 \%$, reducing the ESS score, not worsening comorbidities, and reducing comparative operation time. Furthermore, this surgery is preferable for drug-induced sleep endoscopy grade III-IV lingual tonsil hypertrophy. Vicini et al. reported that the resection tissue volume was significantly correlated with surgical success ${ }^{33}$. However, other studies have reported that the resection tissue volume is not related to surgical success but that creating a relatively stable channel for airway flow is crucial to reducing obstruction severity ${ }^{27,34}$. Therefore, although Vicini et al. suggested resection volume as a factor indicating surgical success ${ }^{33}$, smaller resection volumes can also lead to a significant reduction in the $\mathrm{AHI}$ and increase in the lowest $\mathrm{O}_{2}$ saturation.

Furthermore, more favorable prolonged and sustained airway patenting results could be achieved using the TORS approach compared with radiofrequency (higher recurrence rate because of tissue recovery response) and CTBR (tissue firewall response hinders the resection tongue base volume). High magnification and precision was also possible using TORS, improving the surgical procedure and hemostatic control ${ }^{35}$. Moreover, we believe that the cost-effectiveness of TORS is more favorable than that of other methods. Because of its once for all characteristic and one time multilevel though out surgery, reducing the need for surgical salvage and postoperative continuous positive airway pressure salvage, which increases the effectiveness and reduces the cost of therapy. Friedman et al. indicated that TORS is more expensive but also more efficacious for obstructive sleep apnea than other surgeries ${ }^{6}$. Furthermore, the use of robotic surgery offers improved surgical views during surgery, involves less working trauma to the patient, and adversely affects the health of surgeons less. For instance, the risk of a cervical and lumbar spine condition or wrist injury is lower compared with other traditional intraoral surgical methods. Therefore, TORS is a valuable alternative method for sleep surgeons and patients with obstructive sleep apnea and tongue base problems. The information obtained from the included articles provided numerous insights. However, the present study had limitations. First, most of the articles included were retrospective case studies that lacked details regarding experimental research design, resulting in a high risk of bias in the studies used in our systematic review. Second, TORS is an innovative example of technology-assisted medical treatment. However, the operation time was the only surgical parameter observed in the meta-analysis. Other surgical characteristic parameters were not sufficiently defined in the selected articles, which further limited comparison between TORS and alternative interventions.

\section{Conclusion}

Our systematic review revealed that the use of TORS to treat obstructive sleep apnea had the same success and failure rates as other compared interventions with no statistical difference in operation times. The clinical effects on the AHI, lowest $\mathrm{O}_{2}$ saturation, and ESS score of treatment with TORS were comparable to the effects of alternative surgeries. In addition to TORS, numerous other methods are available for treating obstructive sleep apnea, such as CTBR and radiofrequency.

\section{Data availability}

Data supporting the findings of the current study are available from the corresponding author on reasonable request.

Received: 11 May 2020; Accepted: 12 October 2020

Published online: 23 October 2020

\section{References}

1. Maspero, C., Giannini, L., Galbiati, G., Rosso, G. \& Farronato, G. Obstructive sleep apnea syndrome: A literature review. Miner. Stomatol. 64, 97-109 (2015).

2. Hou, T., Hu, S. \& Jiang, X. Tongue coblation via the ventral approach for obstructive sleep apnea-hypopnea syndrome surgery. Laryngoscope 122, 2582-2586 (2012).

3. de Bonnecaze, G., Vairel, B., Dupret-Bories, A., Serrano, E. \& Vergez, S. Transoral robotic surgery of the tongue base for obstructive sleep apnea: Preliminary results. Eur. Ann. Otorhinolaryngol. Head Neck Dis. 135, 411-415 (2018).

4. Karaman, M. et al. Comparison of fiber delivered $\mathrm{CO}_{2}$ laser and electrocautery in transoral robot assisted tongue base surgery. Eur. Arch. Otorhinolaryngol. 274, 2273-2279 (2017).

5. Cammaroto, G. et al. Tongue reduction for OSAHS: TORSs vs coblations, technologies vs techniques, apples vs oranges. Eur. Arch. Otorhinolaryngol. 274, 637-645 (2017).

6. Friedman, M. et al. Transoral robotic glossectomy for the treatment of obstructive sleep apnea-hypopnea syndrome. Otolaryngol. Head Neck Surg. 146, 854-862 (2012).

7. Sutherland, K., Chan, A. S. L., Ngiam, J., Darendeliler, M. A. \& Cistulli, P. A. Qualitative assessment of awake nasopharyngoscopy for prediction of oral appliance treatment response in obstructive sleep apnoea. Sleep Breath 22, 1029-1036 (2018).

8. Albdah, A. A. et al. The impact of drug-induced sleep endoscopy on therapeutic decisions in obstructive sleep apnea: A systematic review and meta-analysis. Cureus 11, 6041 (2019).

9. Semelka, M., Wilson, J. \& Floyd, R. Diagnosis and treatment of obstructive sleep apnea in adults. Am. Fam Physician 94, 355-360 (2016).

10. Tanna, N. et al. Surgical management of obstructive sleep apnea. Plast. Reconstr. Surg. 137, 1263-1272 (2016).

11. Hwang, C. S. et al. Comparison of robotic and coblation tongue base resection for obstructive sleep apnoea. Clin. Otolaryngol. 43, 249-255 (2018). 
12. Babademez, M. A., Gul, F., Sancak, M. \& Kale, H. Prospective randomized comparison of tongue base resection techniques: Robotic vs coblation. Clin. Otolaryngol. 44, 989-996 (2019).

13. Lan, W. C., Chang, W. D., Tsai, M. H. \& Tsou, Y. A. Trans-oral robotic surgery versus coblation tongue base reduction for obstructive sleep apnea syndrome. PeerJ 7, 7812 (2019).

14. Huntley, C. et al. Comparing upper airway stimulation to transoral robotic base of tongue resection for treatment of obstructive sleep apnea. Laryngoscope 129, 1010-1013 (2019).

15. Yu, J. L., Mahmoud, A. \& Thaler, E. R. Transoral robotic surgery versus upper airway stimulation in select obstructive sleep apnea patients. Laryngoscope 129, 256-258 (2019).

16. Aynacı, E., Karaman, M., Kerşin, B. \& Findık, M. O. Comparison of radiofrequency and transoral robotic surgery in obstructive sleep apnea syndrome treatment. Acta Otolaryngol. 138, 502-506 (2018).

17. Folk, D., \& D’Agostino, M. Transoral robotic surgery vs. endoscopic partial midline glossectomy for obstructive sleep apnea. World J Otorhinolaryngol Head Neck Surg 3,101-105(2017).

18. Heiser, C., Edenharter, G., Bas, M., Wirth, M. \& Hofauer, B. Palatoglossus coupling in selective upper airway stimulation. Laryngoscope 127, 378-383 (2017).

19. Vanderveken, O. M. et al. Evaluation of drug-induced sleep endoscopy as a patient selection tool for implanted upper airway stimulation for obstructive sleep apnea. J Clin Sleep Med 9, 433-438 (2013).

20. Babademez, M. A. et al. Low-temperature bipolar radiofrequency ablation (coblation) of the tongue base for supine-positionassociated obstructive sleep apnea. ORL. J .Otorhinolaryngol. Relat. Spec. 72, 51-55 (2010).

21. Guilleminault, C., Chervin, R., Palombini, L. \& Powell, N. Radiofrequency(pacing and thermic effects) in the treatment of sleepdisordered breathing. Sleep 23, 182-186 (2000).

22. Powell, N. B. et al. Radiofrequency volumetric tissue reduction of the palate in subjects with sleep-disordered breathing. Chest 113, 1163-1174 (1998).

23. Choussein, S., Srouji, S. S., Farland, L. V. \& Gargiulo, A. R. Flexible carbon dioxide laser fiber versus ultrasonic scalpel in robotassisted laparoscopic myome. J. Minim. Invas. Gynecol. 22, 1183-1190 (2015).

24. Remacle, M. et al. Combining a new $\mathrm{CO}_{2}$ laser wave guide with transoral robotic surgery: A feasibility study on four patients with malignant tumors. Eur. Arch. Otorhinolaryngol. 269, 1833-1837 (2012).

25. Murphey, A. W., Kandl, J. A., Nguyen, S. A., Weber, A. C. \& Gillespie, M. B. The effect of glossectomy for obstructive sleep apnea: A systematic review and meta-analysis. Otolaryngol. Head Neck Surg. 153, 334-342 (2015).

26. Lee, J. M., Weinstein, G. S., O’Malley, B. W. Jr. \& Thaler, E. R. Transoral robot-assisted lingual tonsillectomy and uvulopalatopharyngoplasty for obstructive sleep apnea. Ann. Otol. Rhinol. Laryngol. 121, 635-639 (2012).

27. Cammaroto, G. et al. Trans-oral robotic tongue reduction for OSA: Does lingual anatomy influence the surgical outcome?. J. Clin. Sleep Med. 14, 1347-1351 (2018).

28. Hoff, P. T., Glazer, T. A. \& Spector, M. E. Body mass index predicts success in patients undergoing transoral robotic surgery for obstructive sleep apnea. ORL J. Otorhinolaryngol. Relat. Spec. 76, 266-272 (2014).

29. Justin, G. A., Chang, E. T., Camacho, M. \& Brietzke, S. E. Transoral robotic surgery for obstructive sleep apnea: A systematic review and meta-analysis. Otolaryngol. Head Neck Surg. 154, 835-846 (2016).

30. Lin, H. C., Hwang, M. S., Liao, C. C. \& Friedman, M. Taste disturbance following tongue base resection for OSA. Laryngoscope 126, 1009-1013 (2016).

31. Miller, S. C., Nguyen, S. A., Ong, A. A. \& Gillespie, M. B. Transoral robotic base of tongue reduction for obstructive sleep apnea: A systematic review and meta-analysis. Laryngoscope 127, 258-265 (2017).

32. Meccariello, G. et al. Transoral robotic surgery for the management of obstructive sleep apnea: a systematic review and metaanalysis. Eur. Arch. Otorhinolaryngol. 274, 647-653 (2017).

33. Vicini, C. et al. Transoral robotic tongue base resection in obstructive sleep apnoea-hypopnoea syndrome: A preliminary report. ORL J. Otorhinolaryngol. Relat. 72, 22-27 (2010).

34. Bahgat, A. et al. Transoral endoscopic coblation tongue base surgery in obstructive sleep apnea: Resection versus ablation. ORL J. Otorhinolaryngol. Relat. Spec 82, 201-208 (2020).

35. O’Malley, B. W. Jr., Weinstein, G. S., Snyder, W. \& Hockstein, N. G. Transoral robotic surgery (TORS) for base of tongue neoplasms. Laryngoscope 116, 1465-1472 (2006).

\section{Author contributions}

T.Y and C.W. wrote the main manuscript text and all figures. All authors reviewed the manuscript.

\section{Funding}

There are no funders to report for this submission.

\section{Competing interests}

The authors declare no competing interests.

\section{Additional information}

Correspondence and requests for materials should be addressed to W.-D.C.

Reprints and permissions information is available at www.nature.com/reprints.

Publisher's note Springer Nature remains neutral with regard to jurisdictional claims in published maps and institutional affiliations.

(c) (i)

Open Access This article is licensed under a Creative Commons Attribution 4.0 International License, which permits use, sharing, adaptation, distribution and reproduction in any medium or format, as long as you give appropriate credit to the original author(s) and the source, provide a link to the Creative Commons licence, and indicate if changes were made. The images or other third party material in this article are included in the article's Creative Commons licence, unless indicated otherwise in a credit line to the material. If material is not included in the article's Creative Commons licence and your intended use is not permitted by statutory regulation or exceeds the permitted use, you will need to obtain permission directly from the copyright holder. To view a copy of this licence, visit http://creativecommons.org/licenses/by/4.0/.

(C) The Author(s) 2020 